\title{
Finite Element Analysis of Changes in Tensile Strain by Airsoft Gun Impact on Eye and Deformation Rate in Eyes of Various Axial Lengths
}

This article was published in the following Dove Press journal: Clinical Ophthalmology

\section{Rie Takahashi \\ Kanno Okamura \\ Tomoko Tsukahara- \\ Kawamura (D) \\ Kazuhiro Harada \\ Yusuke Saeki \\ Hiroaki Ozaki \\ Eiichi Uchio (D)}

Department of Ophthalmology, Fukuoka University School of Medicine, Fukuoka, Japan
Correspondence: Eiichi Uchio

Department of Ophthalmology, Fukuoka

University School of Medicine, 7-45-1

Nanakuma, Fukuoka, Jonan-Ku 8|4-0|80, Japan

Tel +81928011011

Fax +81928654445

Email euchio@fukuoka-u.ac.jp
Purpose: We have carried out three-dimensional finite element analysis (FEA) to determine the physical and mechanical response in several ocular injuries. We applied this FEA model to evaluate an airsoft gun impact on an eye and the deformation rate of eyes of various axial lengths at various velocities.

Methods: This study was carried out on a human eye model using an FEA program created by Nihon, ESI Group. The airsoft gun pellet was set to impact the eye at initial velocities of 45,60 and $75 \mathrm{~m} / \mathrm{s}$ with the addition of variation in axial length of $20 \mathrm{~mm}$ (hyperopia), $22 \mathrm{~mm}$ (emmetropia), $24 \mathrm{~mm}$ (myopia) and $26 \mathrm{~mm}$ (high myopia). Deformation of the eye was calculated as the decrease rate of the volume of the eyeball and the decrease rate of the axial length.

Results: In all emmetropic cases, the cornea reached its strain threshold during the impact, and scleral strain showed a patchy strength distribution in the simulation. The deformation was most evident in the anterior segment, while deformation of the posterior segment was less. The decrease rate of the volume of the eyeball and decrease rate of the axial length were highest in the hyperopic eye, followed by the emmetropic eye and myopic eye, and the high myopic eye showed the lowest decrease rates among the four axial lengths in all impact velocity simulations.

Conclusion: These results suggest that hyperopic eyes are most susceptible to deformation by an airsoft gun impact compared with other axial length eye models in this simulation. The considerable deformation by an airsoft gun impact shown in this study might indicate the necessity of ocular protection to avoid permanent eye injury. FEA using a human eyeball model might be a useful method to analyze and predict the mechanical features of ocular injury by an airsoft gun.

Keywords: airsoft gun, finite element analysis, globe, cornea, rupture, deformation

\section{Introduction}

Airsoft guns are commonly referred to as BB guns or pellet guns, as they also launch spherical projectiles (typically through a smoothbore barrel). Common airsoft gun bullets are $6 \mathrm{~mm}$ in diameter ( $0.24 \mathrm{inch})$ and are generally made of plastic or other non-metallic materials specifically designed to impart low target damage. Using a BB shot, the effective flight range and maximum speed of a metal bullet with this gun are two times higher than those of plastic bullets with other airsoft guns. ${ }^{1} \mathrm{BB}$ guns can cause several kinds of ocular injuries in not only the anterior segment but also the posterior segment, including chorioretinitis sclopetaria, intraocular foreign body (IOFB), perforating injury 
or even rupture, which frequently lead to enucleation $(27-93 \%) .^{2-6}$ These characteristics have made this gun potentially vision threatening. Airsoft gun impact can result in severe ocular damage, significant loss of vision, and, in extreme cases, complete loss of the eye. ${ }^{7}$ Most injuries require immediate emergency surgery and numerous follow-up surgeries. It is well known that airsoft gun ocular injury is a frequent cause of blunt ocular trauma in children. ${ }^{8-10}$ Ocular injuries caused by airsoft guns including BB guns have been widely reported in the literature recently, ${ }^{1-6,8-10}$ but there are only a few studies evaluating the clinicopathological mechanism of airsoft gun ocular injuries. Two studies have been reported; one evaluated different projectiles in matched experimental eye impact simulations, ${ }^{11}$ and one performed numerical modeling of paintball impact ocular trauma. $^{12}$

Therefore, we planned to study the kinetic phenomenon of airsoft gun impact on a human eye using a simulation method that was applied to our previous several studies. ${ }^{13-17}$ If we are able to reproduce the kinetic phenomena including intraocular deformation caused by an airsoft gun impact sequentially, this will increase understanding of the pathophysiological mechanism of blunt ocular trauma by an airsoft gun. Although wearing effective eye protection has been shown to mitigate or entirely eliminate many ocular injuries, children quite often fail to use proper safety equipment, especially during unsupervised activities where most injuries occur. For this reason, it has been suggested that the most practical solution is the development of a safer airsoft gun bullet, one that greatly reduces the risk and severity of injury during direct impact with the eye. However, before this can be accomplished, a fundamental understanding of the relationship between airsoft gun characteristics (materials and impact parameters) and ocular trauma must be developed.

From these factors, in this study, we introduced a simulation model to determine the biomechanical response caused by impacting an airsoft gun on a model eye at various velocities and the deformation rate after an airsoft gun impact on eyes of various axial lengths.

\section{Materials and Methods}

A model human eye was created and used in simulations with a computer using an FEA program, PAM-GENERIS ${ }^{\mathrm{TM}}$ (Nihon ESI, Tokyo, Japan), described elsewhere. ${ }^{13}$ The meshing principles of the model eye are shown in Figure 1A according to the previous reports. ${ }^{13,14}$ A vitreous model as a solid mass with a hydrostatic pressure of $20 \mathrm{mmHg}(2.7$ $\mathrm{kPa}$ ) was also assigned.
A biomechanical head of a dummy was created, assuming that everything excluding the eye was a solid element, to reduce the computing time. The Hybrid III model was modified by replacing the head of the dummy with a biomechanical model of the head in which an eye was inserted. ${ }^{18,19}$ An airsoft gun pellet $(0.2 \mathrm{~g})$, with $6 \mathrm{~mm}$ diameter and higher rigidity than an eyeball, was set to impact the eyeball in a straight position (Figure 1B) at three different velocities of 45,60 and $75 \mathrm{~m} / \mathrm{s}$. This gun pellet was in accordance with a so-called BB shot. ${ }^{20}$ The reference point for globe rupture was then calculated to be at a strain of $18.0 \%$ and stress of $9.45 \mathrm{MPa}$ for the cornea, and at a strain of $6.8 \%$ and stress of $9.49 \mathrm{MPa}$ for the sclera, which exceeded the tensile tolerance based on element deletion method. ${ }^{14}$ As for axial length of the eyeball, four axial lengths, 20, 22, 24 and $26 \mathrm{~mm}$, were introduced, and each length was assumed to correspond to hyperopia, emmetropia, myopia and high myopia, respectively. In each model, ocular elements were shortened or elongated according to the proportion against the normal eye (emmetropia) on optic axis direction, but diameters in the frontal view were not changed.

Changes in the shape of the eye and the strain induced were calculated by Virtual Performance Solver (VPS) (Nihon ESI) and evaluated by color mapping (Figure 1C). Deformation of the eye in a cross-sectional view was displayed sequentially in milliseconds in slow motion. Deformation of the eye was calculated in brief as the decrease rate of the volume of the eyeball and the decrease rate of the axial length as the integrated value of all meshes simulated in comparison with the values before the airsoft gun impact.

\section{Results}

Because of the three impact velocities of the airsoft gun (45, 60 and $75 \mathrm{~m} / \mathrm{s}$ ) and four axial lengths (20 (hyperopia), 22 (emmetropia), 24 (myopia) and 26 (high myopia) $\mathrm{mm}$ ), twelve cases were simulated sequentially from the primary impact to the eyeball until $0.2 \mathrm{~ms}$ after the primary impact. The results of each simulation are shown in the frontal view, side view and cross-sectional view of the deformed globe in original image, we have gained abundant data from this study; however, it is difficult to display all these results. Thus, maximum strain observed in the frontal view in emmetropia and all simulations in the cross-sectional view were presented as follows.

For simplification, strain strength response of the ocular surface, cornea and sclera, was evaluated in a case of 




A

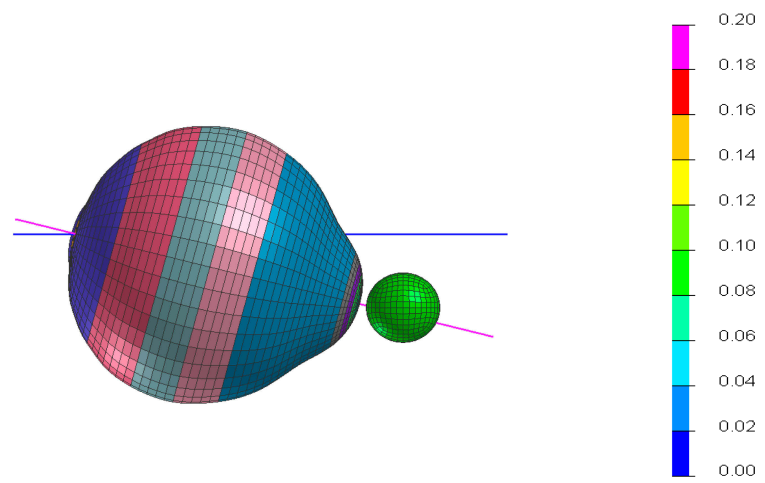

B

C

Figure I Simulation profile of model eye and deformation scale. (A) Diagonal view of model eye and meshing principles of finite element analysis. (B) Eyeball and impacting airsoft gun location in straight position. (C) Color mapping scale of deformation of eye showing strain induced; warmer color of red represents greater deformation.

normal axial length eye (emmetropia) with an airsoft gun impact. In the case of an impact velocity of $45 \mathrm{~m} / \mathrm{s}$, corneal strain reached its threshold $(18.0 \%)$ at $0.02 \mathrm{~ms}$ after the impact in the simulation (Figure 2A). When the airsoft gun impacted at 60 and $75 \mathrm{~m} / \mathrm{s}$, corneal laceration was observed at $0.02 \mathrm{~ms}$ (Figure 2B) and $0.01 \mathrm{~ms}$ (Figure 2C) after the impact in the simulation, respectively. In all these cases, scleral strain showed a patchy strength distribution in the simulation (Figure 2A-C).

Ocular deformation after an airsoft gun impact was displayed sequentially in a cross section at impact velocities of $45 \mathrm{~m} / \mathrm{s}$ (Figure 3A), $60 \mathrm{~m} / \mathrm{s}$ (Figure 3B) and $75 \mathrm{~m} / \mathrm{s}$ (Figure $3 \mathrm{C}$ ), and the results of four axial length simulations are shown. In each case, the eyeball was shortened after the airsoft gun impact, which was most evident in the cornea, and the deformation continued and extended toward the end of the simulation. Deformation of the vitreous body was less than that of the cornea. The anterior chamber and lens were both susceptible to strong deformation, which seemed to disappear especially in high impact velocity $(75 \mathrm{~m} / \mathrm{s}$; Figure $3 \mathrm{C}$ ). The decrease rate of the volume of the eyeball and decrease rate of the axial length are shown in Tables 1 and 2, respectively. Both rates were highest in the hyperopic eye followed by the emmetropic eye and myopic eye, and those in the highly myopic eye were the lowest among the four axial lengths in all impact velocity simulations (Tables 1 and 2). From these results, it was shown that hyperopic eyes are the most susceptible to deformation by an airsoft gun impact compared with other axial length eye models in this simulation.

\section{Discussion}

It has been reported that ocular injuries associated with airsoft guns are usually confined to the anterior segment and are not so serious, ${ }^{10}$ and common injuries caused by airsoft gun impact include corneal abrasion, hyphema, lens dislocation and cataract. ${ }^{8-10}$ Ocular deformation displayed sequentially in a cross section after the impact in this study showed that axial length shortening after the airsoft gun impact continued and extended toward the end of the simulation, and deformation was most evident in the anterior segment and deformation of the vitreous body was less than that of the cornea (Figure 3 ). The results of our simulation thus support past clinical reports. ${ }^{8-10}$

However, it has also been pointed out that retinal detachment, choroidal rupture, and globe rupture (commonly leading to complete loss of the eye) are observed in some cases of airsoft gun impact. ${ }^{8-10}$ It is reported that injuries caused especially by a BB shot usually cause severe ocular injuries, including IOFB, perforating injury or even globe rupture, which frequently lead to enucleation $(27-93 \%) .^{2-5,9}$ The present study indicated the possibility of globe rupture due to corneal laceration by a airsoft gun impact at 60 or $75 \mathrm{~m} / \mathrm{s}$ in the simulation (Figure 2B and C), and these findings support the recent case series reports of penetrating ocular injury caused by BB shots. ${ }^{9}$ Open globe injuries related to $\mathrm{BB}$ or pellet guns result in devastating visual outcomes, and are often associated with multiple complications and the need for additional surgery and a poor visual prognosis even when treated with modern surgical techniques. ${ }^{8}$ From this 
A





$0.1 \mathrm{~ms}$

$0.14 \mathrm{~ms}$ $0.2 \mathrm{~ms}$

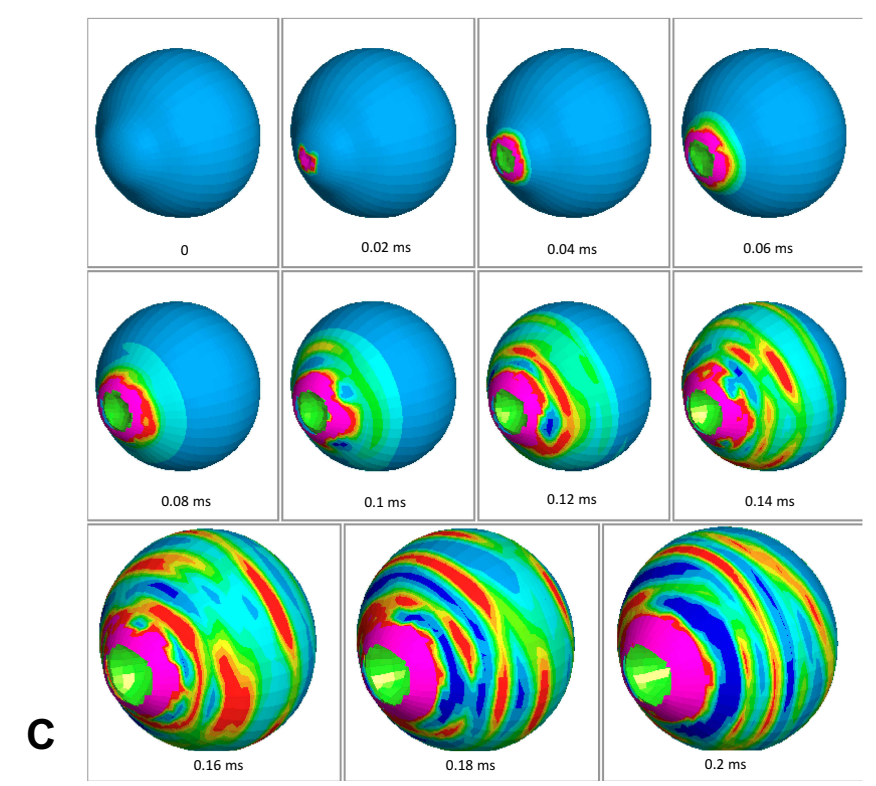

Figure 2 Sequential deformation of model eye upon airsoft gun impact at three different velocities. Cases of impact velocity of 45 (A), 60 (B) and $75 \mathrm{~m} / \mathrm{s}$ (C) in emmetropic eye are shown. Strain strength change is displayed in color as presented in the color bar scale (Figure IC).

study, the decrease rate of the volume of the eyeball and the decrease rate of the axial length were highest in the hyperopic eye followed by the emmetropic eye, meaning that hyperopic eyes are most susceptible to deformation by an airsoft gun impact among axial length eye models in the simulation. However, no study has considered the relationship between axial length and clinical outcome after an impacting foreign body such as from an airsoft gun. Because of the small number of cases of this kind of blunt ocular trauma, this lack of past publications can be understood. Documented clinical profiles of airsoft gun ocular injury indicate that the average age of cases was young, ${ }^{8-10,21-24}$ and considering that the majority of the case series were pediatric cases including immature adolescent eyes, our results might indicate the necessity of ocular protection to avoid permanent eye injury. ${ }^{23,24}$

The use of airsoft guns is common among children because they look real, are cheap and have no restrictions. The considerable deformation by an airsoft gun impact shown in this study (Figure 3) might suggest that unsupervised access to these guns is likely to be the principal risk factor for these injuries, which implies the importance of political strategies targeting parental education and restriction of children's access to these guns. ${ }^{7,25}$ 


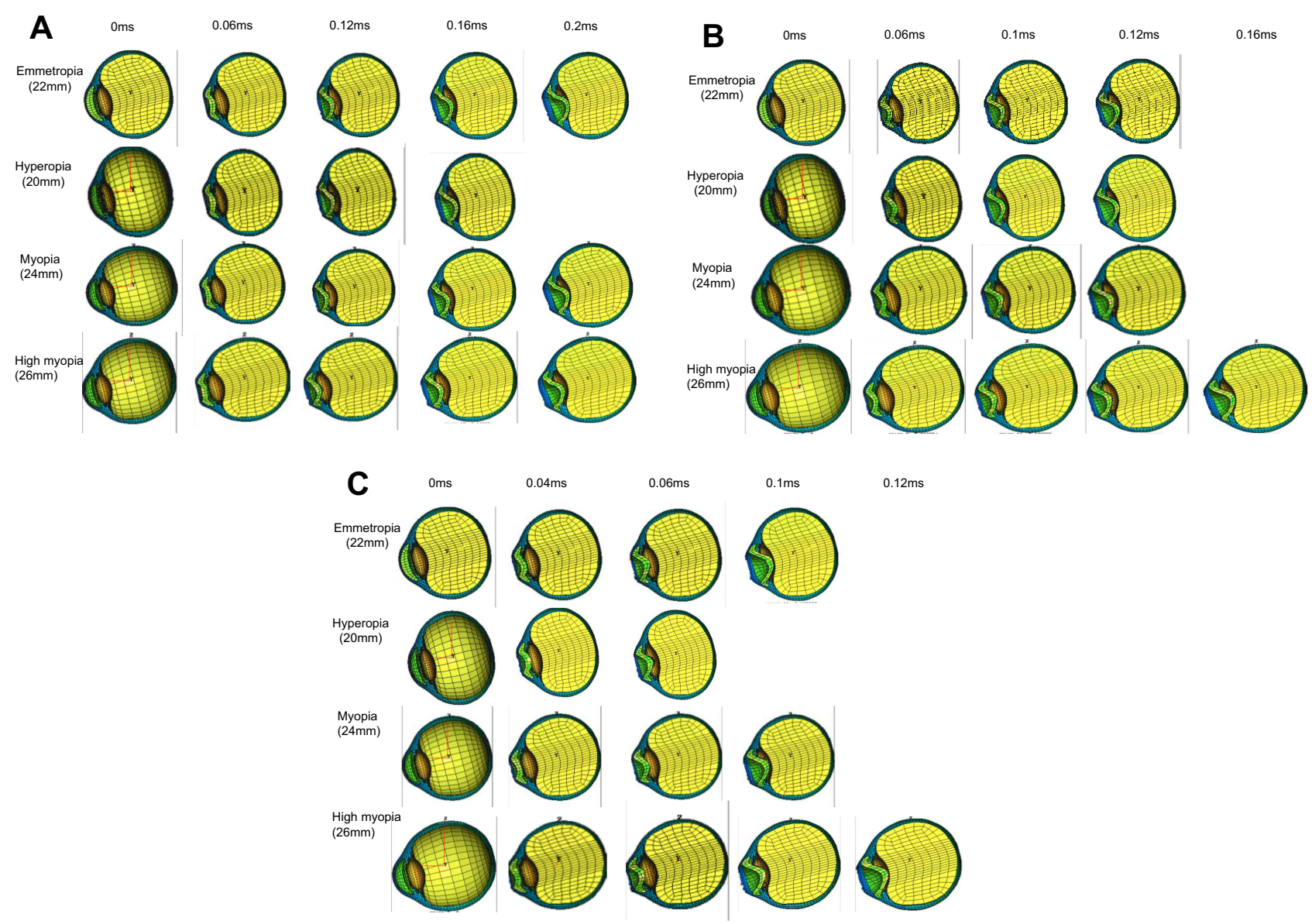

Figure 3 Ocular deformation after airsoft gun impact displayed sequentially in cross-sectional view at three impact velocities for four axial length eyes. (A) Cases of impact velocity of $45 \mathrm{~m} / \mathrm{s}$. (B) Cases of impact velocity of $60 \mathrm{~m} / \mathrm{s}$. (C) Cases of impact velocity of $75 \mathrm{~m} / \mathrm{s}$.

There are several limitations to this study. First, in several simulation cases, especially those with high impact velocity, although graphic output continued, there is a possibility that corneoscleral laceration occurred and further simulation might differ from the clinical findings such as globe rupture. Due to the initial setting of this simulation study, visual output cannot be discontinued in the present version of software. A highvelocity airsoft gun pellet has a tendency to move into the eyeball due to its high energy (Figure $2 \mathrm{~B}$ and $\mathrm{C}$ ). These results, on the other hand, reflect the possibility of an IOFB injury

Table I Decrease Rate of Volume of Eyeball at $0.1 \mathrm{~ms}$ After Impact of Airsoft Gun

\begin{tabular}{|l|l|l|l|}
\hline $\begin{array}{l}\text { Impact Velocity (m/s) } \\
\text { Axial Length Status }\end{array}$ & $\mathbf{4 5}$ & $\mathbf{6 0}$ & $\mathbf{7 5}$ \\
\hline Emmetropia $(22 \mathrm{~mm})$ & $20.1 \%$ & $16.4 \%$ & $31.8 \%$ \\
Hyperopia $(20 \mathrm{~mm})$ & $22.4 \%$ & $28.0 \%$ & $37.3 \%$ \\
Myopia $(24 \mathrm{~mm})$ & $17.9 \%$ & $25.2 \%$ & $28.6 \%$ \\
High myopia $(26 \mathrm{~mm})$ & $16.4 \%$ & $18.7 \%$ & $23.5 \%$ \\
\hline
\end{tabular}

from an air gun pellet as a small object penetrating injury. The high incidence of globe rupture caused by an airsoft gun also supports this hypothesis, ${ }^{8,9}$ and further evaluation in a future simulation study is anticipated. Secondly, we introduced the decrease rate of the volume of the eyeball and the decrease rate of the axial length to evaluate the relationship between strength deformation of the eyeball and the development of serious blunt intraocular injury, such as traumatic cataract, retinal detachment or vitreous hemorrhage, ${ }^{8-10}$ while several other factors, such as intraocular pressure, eye position at

Table 2 Decrease Rate of Axial Length at 0.1 ms After Impact of Airsoft Gun

\begin{tabular}{|l|l|l|l|}
\hline $\begin{array}{l}\text { Impact Velocity (m/s) } \\
\text { Axial Length Status }\end{array}$ & $\mathbf{4 5}$ & $\mathbf{6 0}$ & $\mathbf{7 5}$ \\
\hline Emmetropia $(22 \mathrm{~mm})$ & $14.7 \%$ & $18.5 \%$ & $24.1 \%$ \\
Hyperopia $(20 \mathrm{~mm})$ & $17.3 \%$ & $21.8 \%$ & $29.6 \%$ \\
Myopia $(24 \mathrm{~mm})$ & $12.0 \%$ & $17.4 \%$ & $24.0 \%$ \\
High myopia $(26 \mathrm{~mm})$ & $8.1 \%$ & $12.8 \%$ & $16.0 \%$ \\
\hline
\end{tabular}


impact and vitreous liquefaction, might have some effects in airsoft gun injury. However, using our FEA of a model eye enabled us to calculate changes in the eyeball quantitatively in the simulation. Further refinement of computer technology will enable us to carry out more accurate simulation of airsoft gun ocular impact that is closer to the clinical situation, leading to a better explanation of clinical results and the mechanism regarding blunt ocular trauma.

\section{Acknowledgments}

This work was supported by a Grant-in-Aid for Encouragement of Scientists (15K10911) from the Ministry of Education, Science, Sports and Culture of Japan. We thank Dr W. Gray for editing this manuscript.

\section{Disclosure}

The authors report no conflict of interest in this work.

\section{References}

1. Fleischhauer JC, Goldblum D, Frueh BE, Koerner F. Ocular injuries caused by airsoft guns. Arch Ophthalmol. 1999;117(10):1437-1439.

2. Brown GC, Tasman WS, Benson WE. BB-gun injuries to the eye. Ophthalmic Surg. 1985;16(8):505-508.

3. Newman TL, Russo PA. Ocular sequelae of BB injuries to the eye and surrounding adnexa. J Am Optom Assoc. 1998;69(9):583-590.

4. Shanon A, Feldman W. Serious childhood injuries caused by air guns. CMAJ. 1991;144(6):723-725.

5. Sternberg P Jr, de Juan E Jr, Green WR, Hirst LW, Sommer A. Ocular BB injuries. Ophthalmology. 1984;91(10):1269-1277. doi:10.1016/ S0161-6420(84)34159-8

6. Kuhn F, Morris R, Witherspoon CD, Mester V. The Birmingham Eye Trauma Terminology system (BETT). J Fr Ophthalmol. 2004;27 (2):206-210. doi:10.1016/S0181-5512(04)96122-0

7. Schein OD, Enger C, Tielsch JM. The context and consequences of ocular injuries from air guns. Am J Ophthalmol. 1994;117 (4):501-506. doi:10.1016/S0002-9394(14)70011-X

8. Aziz M, Patel S. BB gun-related open globe injuries. Ophthalmol Retina. 2018;2(10):1056-1061. doi:10.1016/j.oret.2018.03.006

9. Ahmadabadi MN, Karkhaneh R, Valeshabad AK, Tabatabai A, Jager MJ, Ahmadabadi EN. Clinical presentation and outcome of perforating ocular injuries due to BB guns: a case series. Injury. 2011;42(5):492-495. doi:10.1016/j.injury.2010.11.006

10. Ramstead C, Ng M, Rudnisky CJ. Ocular injuries associated with airsoft guns: a case series. Can J Ophthalmol. 2008;43(5):584-587. doi:10.3129/108-131
11. Weaver AA, Kennedy EA, Duma SM, Stitzel JD. Evaluation of different projectiles in matched experimental eye impact simulations. J Biomech Eng. 2011;133(3):031002. doi:10.1115/ 1.4003328

12. Gray W, Sponsel WE, Scribbick FW, et al. Numerical modeling of paintball impact ocular trauma: identification of progressive injury mechanisms. Invest Ophthalmol Vis Sci. 2011;52(10):7506-7513. doi:10.1167/iovs.11-7942

13. Uchio E, Ohno S, Kudoh J, Aoki K, Kisielewicz LT. Simulation model of an eyeball based on finite element analysis method on a supercomputer. $\mathrm{Br} J$ Ophthalmol. 1999;3(10):1106-1111. doi:10. 1136/bjo.83.10.1106

14. Uchio E, Ohno S, Kudoh K, Kadonosono K, Andoh K, Kisielewicz LT. Simulation of airbag impact on post-radial keratotomy eye using finite element analysis. J Cataract Refract Surg. 2001;27(11):1847-1853. doi:10.1016/S0886-3350(01)00966-X

15. Uchio E, Watanabe Y, Kadonosono K, Matsuoka Y, Goto S. Simulation of airbag impact on eyes with transsclerally fixated posterior chamber intraocular lens using finite element analysis. $J$ Cataract Refract Surg. 2004;30(2):483-490. doi:10.1016/S08863350(03)00520-0

16. Uchio E, Kadonosono K, Matsuoka Y, Goto S, Goto S. Simulation of airbag impact on eyes after photorefractive keratectomy by finite element analysis method. Graefes Arch Clin Exp Ophthalmol. 2003;241(6):497-504. doi:10.1007/s00417-003-0679-8

17. Huang J, Uchio E, Goto S. Simulation of airbag impact on eyes with different axial lengths after transsclerally fixated posterior chamber intraocular lens by using finite element analysis. Clin Ophthalmol. 2015;9:263-270. doi:10.2147/OPTH.S75180

18. Buzard KA. Introduction to biomechanics of the cornea. Refract Corneal Surg. 1992;8(2):127-138.

19. Ruan JS, Prasad P. Coupling of a finite element human head model with a lumped parameter Hybrid III dummy model: preliminary results. J Neurotrauma. 1995;12(4):725-734. doi:10.1089/neu.1995.12.725

20. Jiang B, Zhu F, Cao L, Presley BR, Shen MS, Yang KH. Computational study of fracture characteristics in infant skulls using a simplified finite element model. J Forensic Sci. 2017;62 (1):39-49. doi:10.1111/1556-4029.13241

21. Shuttleworth GN, Galloway P, Sparrow JM, Lane C. Ocular air gun injuries: a one-year surveillance study in the UK and Eire (BOSU). 2001-2002. Eye (Lond). 2009;23(6):1370-1376. doi:10.1038/ eye. 2008.275

22. Shuttleworth GN, Galloway PH. Ocular air-gun injury: 19 cases. $J$ R Soc Med. 2001;94(8):396-399. doi:10.1177/01410768010940 0806

23. Lee R, Fredrick D. Pediatric eye injuries due to nonpowder guns in the United States, 2002-2012. J AAPOS. 2015;19(2):163-168. doi:10.1016/j.jaapos.2015.01.010

24. Rudd JC, Jaeger EA, Freitag SK, Jeffers JB. Traumatically ruptured globes in children. J Pediatr Ophthalmol Strabismus. 1994;31 (5):307-311.

25. Enger C, Schein OD, Tielsch JM. Risk factors for ocular injuries caused by air guns. Arch Ophthalmol. 1996;114(4):469-474. doi:10.1001/archopht.1996.01100130465019
Clinical Ophthalmology

\section{Publish your work in this journal}

Clinical Ophthalmology is an international, peer-reviewed journal covering all subspecialties within ophthalmology. Key topics include: Optometry; Visual science; Pharmacology and drug therapy in eye diseases; Basic Sciences; Primary and Secondary eye care; Patient Safety and Quality of Care Improvements. This journal is indexed on PubMed
Central and CAS, and is the official journal of The Society of Clinical Ophthalmology (SCO). The manuscript management system is completely online and includes a very quick and fair peer-review system, which is all easy to use. Visit http://www.dovepress.com/ testimonials.php to read real quotes from published authors.

\section{Dovepress}

